DOI 10.37882/2223-2982.2021.06.16

\title{
ОСОБЕННОСТИ ФИЗИЧЕСКОЙ ПОДГОТОВКИ В УСЛОВИЯХ ПАНДЕМИИ COVID-19
}

\section{FEATURES OF PHYSICAL TRAINING IN THE CONTEXT OF THE COVID-19 PANDEMIC}

A. Ivanov

A. Khomutov

Summary: The article presents the results of a theoretical study aimed at identifying the advantages and disadvantages in the organization of the discipline "Physical Training» in the universities of the Ministry of Internal Affairs of the Russian Federation during the coronavirus infection COVID-2019. A retrospective analysis of the organization of training of cadets of universities of the Ministry of Internal Affairs of the Russian Federation, as well as data obtained at the end of the period of self-isolation, indicating the dynamics of the level of readiness achieved by students, allowed us to conclude that it is possible to use distance learning tools to solve many problems of knowledge translation. Along with the above, this study focuses on the need to take into account the existing interdependence between the possibility of distance learning and the level of readiness of all subjects of the pedagogical process, which can significantly affect the quality of the implementation of the program material of the discipline «Physical Training». In the course of the study, it was found that as a solution to this problem aspect, it is possible to use additional methods of monitoring and evaluating practical tasks performed by students, which in turn requires additional research focused on the development of remote methods for evaluating the tools used and strengthening the software used in the educational process of all structural divisions of universities.

Keywords: coronavirus infection, distance learning, cadets and trainees, law enforcement agencies, physical training.
Иванов Алексей Алексеевич

Московский университет МВД России имени В.Я. Кикотя

ExeleX001@mail.ru

Хомутов Александр Михайлович

старший преподаватель, Московский Университет

МВД России имени В.Я. Кикотя

Аннотация: В статье представлены результаты теоретического исследования, целью которого стало выявление преимуществ и недостатков в организации дисциплины «Физическая подготовка» в вузах МВД РФ во время коронавирусной инфекции COVID-2019. Ретроспективный анализ организации обучения курсантов ВУЗов МВД РФ, а также данные, полученные по окончанию периода самоизоляции, свидетельствующие о динамике достигнутого обучающимися уровня подготовленности, позволили сделать вывод 0 возможности использования инструментария дистанционного обучения для разрешения многих проблем трансляции знаний. Наряду с отмеченным, в настоящем исследовании акцентировано внимание на необходимости учета существующей взаимозависимости между возможностью осуществления дистанционного обучения и уровнем подготовленности всех субъектов педагогического процесса, способной значимо отразиться на качестве процесса реализации программного материала дисциплины «Физическая подготовка». В ходе исследования было установлено, что в качестве решения названного проблемного аспекта возможно использование дополнительных методов контроля и оценки практических заданий, выполняемых обучающимися, что в свою очередь требует дополнительных исследований, ориентированных на разработку дистанционных способов оценки применяемых средств и усиление программного обеспечения, используемого в учебновоспитательном процессе всех структурных подразделений ВУЗов.

Ключевые слова: коронавирусная инфекция, дистанционное обучение, курсанты и слушатели, правоохранительные органы, физическая подготовка.

\section{Введение}

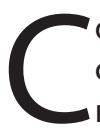
обытия 2020 года, вошедшего в историю развития современного общества как год распространения коронавирусной инфекции (COVID-19), обусловили целый спектр достаточно серьезных трансформаций, последствия которых отразились на деятельности во всех отраслях жизнедеятельности человека, включая и сферу образования. При этом, кардинальные изменения можно отметить не только в структурной организации педагогического процесса, но и в его содержательном наполнении, выявив в ходе вынужденного реформирования наиболее болезненные «реперные точки», определив приоритетные направления многих исследований на ближайшее время [1, с.23]. В контексте затронутой нами темы, следует акцентировать внимание на слож- ности разрешения сложившейся ситуации и ряде проблемных вопросов, возникших в период пандемии в организации образовательного процесса по учебной дисциплине «Физическая подготовка» в ВУЗах силовых ведомств, в том числе и Министерства внутренних дел Российской Федерации (далее - МВД РФ). Особенно остро встал вопрос о пересмотре вариативности преподавания и освоения учебного материала курсантами по дисциплине «Физическая подготовка» [1, с.24].

\section{Теоретический анализ проблемы исследования}

Опираясь на Распоряжение Министра внутренних дел Российской Федерации №1/3768 от 03 апреля 2020 г. [6] и поручение Правительства РФ от 25 марта 2020 г. № ДГ-П17-2301кв [4] подготовленных с целью предот- 
вращения распространения COVID-19, среди личного состава органов внутренних дел РФ вузы МВД России, организация педагогического процесса в ВУЗах МВД РФ была переведена на дистанционное обучение, что предусматривает освоение учебного материала курсантами, включая и таких практико-ориентированных дисциплин как «Физическая подготовка» на период самоизоляции посредством использования системы дистанционных образовательных технологий (далее - СДОТ). Сложившаяся ситуация, характеризуемая автоматизацией образовательного процесса, обусловило дистанцирование во взаимодействиях всех субъектов, задействованных в процессе обучения, что не могло не отразиться на формате освоения программы по учебной дисциплине «Физическая подготовка» [3, с.128]. Следует отметить, что подобная организация ранее очного формата проведения занятий, не предусмотрена Приказом МВД России от 1 июля 2017 г. № 450 [5] «Об утверждении Наставления по организации физической подготовки в органах внутренних дел Российской Федерации», а значит вызывает противоречие, требующего разрешения.

Ряд учебных заведений, осуществляющих подготовку сотрудников МВД РФ, в период пандемии продолжали использовать в некоторой степени очный формат занятий, естественно с соблюдением санитарно-противоэпидемических и организационно-профилактических мер, привлекая к занятиям только лишь тех сотрудников, которые выполняли оперативно-служебные задачи на территории Северо-Кавказского региона РФ. Основной контингент курсантов, сотрудников и слушателей осваивали программный материал в «заочном режиме» посредством возможностей, предоставляемых современными компьютерными технологиями.

Организация занятий в дистанционном режиме требует от профессорско-преподавательского состава ВУЗа серьезной предварительной подготовки, которая заключается в разработке и способе предоставления знаний, транслируемых в онлайн и офлайн режимах. Особую сложность испытывали преподаватели кафедр физической подготовки, которые были вынуждены осваивать навыки не только электронного транслирования учебной информации, но и осуществлять поиск наиболее оптимальных способов визуализации практико-ориентированных занятий, подразумевающих выработку у курсантов двигательных навыков и организацию достоверной обратной связи, позволяющей произвести оценку и внести своевременные поправки (коррекцию) в действия обучающихся [2, с.91].

В процессе периода ограничений, вызванного распространением коронавирусной инфекции, процесс обучения по дисциплине «Физическая подготовка» не только обострила уже имеющиеся специфические особенности, но и определило необходимость пересмотра ранее разработанного учебного материала в контексте его эффективного преподнесения в ходе организации практических занятий. Алгоритм преподавания подвергся существенным изменениям, определив не только порядок разработки, но и формирование образовательного контента. Естественно, что приобретение курсантами необходимых практических навыков (приёмов задержания правонарушителя, проведения наружного досмотра и т.д.) посредством ЭИОС, предполагало построение дополнительного алгоритма фиксирования хода выполнения заданий, оценку осуществляемых обучающимися действий по результатам видеозаписей, а также выработку имитационных упражнений, предполагающих выполнение в парах (соперника), в связи с ограничением тактильных контактов. Безусловно, электронная почта, или группы в Whats Apр или Viber не способны полностью заменить освоение практических навыков в ходе непосредственного контакта, в частности по разделу «Боевые приёмы борьбы», а негативные последствия дистанционных занятий отмечались специалистами и преподавателями уже с началом нового учебного года.

В контексте сказанного следует отметить, что указанные нами ограничения вызывают тревогу со стороны преподавателей кафедр физической подготовки, так как значительная часть времени, несмотря на попытки интеграции в рамках предоставленных вышеназванных документов возможностей, не позволяет полностью выполнить требования, предъявляемые к уровню подготовленности сотрудников МВД РФ. Конечно, в период самоизоляции все задания, предполагающие практическое воплощение, были перенесены в онлайн режим, что отразилось на распределении нагрузки преподавателей, которые в большей степени были заняты разработкой заданий по общефизической подготовке (далее - ОФП) курсантов, адаптируя их под условия мест проживания обучающихся. При разработке занятий были использованы методики, представленные в системах общей и специальной физической подготовки известных спортсменов, представляющих своё видение поддержания спортивной формы в домашних условиях. Найденные методики проходили этапы адаптации и апробации сотрудниками кафедры, и только после этого предлагались к выполнению обучающимся, с учетом уровня их физической подготовленности. Серьезным ударом по уровню физической подготовки стал запрет на проведение физкультурных мероприятий и спортивных соревнований, который негативно отразился на всем педагогическом процессе.

В целом, следует признать высокие возможности, предоставляемые современными техническими средствами, которые были задействованы в условиях пандемии с целью сохранения достигнутого курсантами уровня физической подготовленности, что достигалось посредством визуализации и поддержания диалога. Од- 
нако, для достижения высокого уровня действенности имеющегося в дистанционном обучении инструментария, необходимо наличие оперативного умения продвинутого пользователя компьютера, знания которого позволяют полноценно провести видеоконференцию, владение приёмами осуществления текущего контроля путем опроса и тестирования в условиях дистанционного обучения и многое другое, требующие больших временных затрат, выходящих за рамки предоставленного учебными программами.

\section{BыBOA}

Таким образом, ретроспективный анализ организации обучения по физической подготовке курсантов ВУЗов МВД РФ, а также данные, полученные по окончанию периода самоизоляции, свидетельствующие о динамике достигнутого обучающимися уровня подготовленности, позволил сделать ряд выводов: 1) дистанционное об- учение позволяет решать многие проблемы трансляции знаний, обладая широким спектром возможностей и эффективным инструментарием, однако полнота его использования обусловлена уровнем подготовленности всех субъектов педагогического процесса (наличие оперативного умения продвинутого пользователя компьютера, учебно-методическое обеспечение процесса обучения и т.д.); 2) в качестве одного из решений проблемного вопроса по осуществлению контроля и оценки выполнения обучающимися практических заданий можно рассматривать лишь количественные изменения в конкретных показателях уровня физической подготовленности, однако сохранение и повышение качества их выполнения требует дополнительных исследований, ориентированных на разработку дополнительных (дистанционных) способов оценки контрольных средств, требующих усиления программного обеспечения технических средств, используемых в учебно-воспитательном процессе во всех структурных подразделениях ВУЗов.

\section{ЛИТЕРАТУРА}

1. Андриянова, М.В. Дистанционное образование: состояние, тенденции, перспективы развития [Текст] / М.В. Андриянова // Педагогическое образование и наука. - 2020. - № 3. - С. 22 - 24.

2. Блоховцова, Г.Г. и др. Перспективы развития дистанционного обучения [Текст] / Г.Г. Блоховцова, Т.Л. Маликова, А.А. Симоненко// Новая наука: Стратегии и векторы развития. - 2016. - № 118-3. - С. 89 - 92.

3. Васильева, Т.Н. Информационно-педагогические условия внедрения технологии дистанционного обучения в вузах МВД России [Текст] / Т.Н. Васильева // Вестник Санкт-Петербургского университета МВД России. - 2007. - № 1 (33). - С. 125 - 129.

4. Поручение Правительства РФ «0 дополнительных мерах по противодействию коронавирусной инфекции» от 25 марта 2020 г. № ДГ-П17-2301кв [Электронный ресурс]. Режим доступа: https://base.garant.ru/74191715/\#friends (дата обращения: 12.03.2021)

5. Приказ МВД России от 1 июля 2017 г. № 450 «0б утверждении Наставления по организации физической подготовки в органах внутренних дел Российской Федерации» [Электронный ресурс]. Режим доступа: https://www.garant.ru/products/ipo/prime/doc/71647620/ (дата обращения: 12.03.2021).

6. Распоряжение «0б организации освоения образовательных программ с применением исключительно дистанционных образовательных технологий» №1/3768 от 03 апреля 2020 г.[Электронный ресурс]. Режим доступа: http://ios.ruimvd.ru/pluginfile.php?file=\%2F63595\%2Fmod_resource\%2Fcontent\%2F1 \%2Fраспоряжение\%201.37p.PDF (дата обращения: 12.03.2021). 